\title{
The ecology of domestic violence: the role of alcohol outlet density
}

\author{
Michael Livingston \\ School of Population Health, University of Melbourne, Melbourne, Australia and AER Centre for Alcohol \\ Policy Research Turning Point Alcohol and Drug Centre, Fitzroy, Australia
}

\begin{abstract}
Studies have consistently found positive associations between the density of alcohol outlets and levels of violence in areas. Few studies have examined whether this relationship holds for domestic violence. This study assesses whether alcohol outlet density is related to domestic violence and whether this relationship is due to alcohol availability or to co-occurring economic disadvantage and social disorganisation. Cross-sectional data on family incidents, liquor outlets and socio-demographic characteristics were obtained for 217 postcodes in Melbourne, Australia. These data were used to construct models assessing the association between alcohol outlet density and domestic violence, both with and without controlling for socio-demographic factors. Models were tested for spatial autocorrelation, and spatial-error models were developed to control for its influence. Outlet density was significantly associated with rates of domestic violence, even controlling for socio-demographic factors. The density of hotels (pubs) was positively associated with domestic violence rates and the density of restaurants and bars was negatively associated with domestic violence. Socio-economic disadvantage was also associated with domestic violence rates. The density of packaged liquor outlets was not associated with rates of domestic violence. The results present a mixed picture, and further study is required to develop a clearer understanding of the links between alcohol availability and domestic violence.
\end{abstract}

Keywords: alcohol availability, outlet density, violence, Australia.

\section{Introduction}

A substantial number of studies have linked alcohol availability to a range of alcohol-related problems (Gruenewald, 2007; Livingston et al., 2007). In particular, there has been an almost uniform finding from cross-sectional studies that the density of alcohol outlets in an area is positively associated with rates of violence in that area. This finding has been replicated in a wide variety of U.S. settings (e.g. Scribner et al., 1999; Stevenson et al., 1999; Gorman et al., 2001; Lipton and Gruenewald, 2002; Nielsen et al., 2005; Reid et al., 2005;

Corresponding author:

Michael Livingston

AER Centre for Alcohol Policy Research Turning

Point Alcohol and Drug Centre

Gertrude Street, 54-62, Fitzroy 3065, Australia

Tel. +61 38413 8407; Fax +61 394163420

E-mail: michaell@turningpoint.org.au
Gruenewald et al., 2006; Gyimah-Brempong and Racine, 2006) and in handful of Australian studies (Stevenson et al., 1999; Chikritzhs et al., 2007; Livingston, 2008a). An increasing number of longitudinal analyses have also found significant associations between alcohol outlet density and violence over time, providing stronger evidence that the relationship is causal (Norström, 2000; Gruenewald and Remer, 2006; Livingston, 2008b; Yu et al., 2008). These studies have focussed on assault rates, using either hospital or police data to estimate the rates of violence occurring in geographical areas. Thus, the violence generally examined in the current literature is largely public violence, often taking place in and around licensed premises. It is worth noting that Freisthler and colleagues have undertaken a series of studies that have demonstrated statistical associations between alcohol outlet density and child abuse and maltreatment, both cross-sectionally (Freisthler, 2004; Freisthler et al., 2004, 2005, 
2007) and over time (Freisthler and Weiss, 2008).

Studies of the relationship between alcohol outlet density and domestic violence are less common. Gorman et al. (1998) examined the association between outlet density and domestic violence (largely made up of intimate-partner violence, but also including violence against children), finding no relationship once socio-economic factors were controlled for. An Australian study examined police data using assaults on private premises as a measure for domestic violence, finding that total volume of beer sold in a region was related to rates of violence, but that geographic measures of outlet density (i.e. outlets per $\mathrm{km}^{2}$ ) were not (Chikritzhs et al., 2007). In a recent paper, McKinney et al. (2009) used survey and ecological data in a multi-level study of selfreported intimate-partner violence. Their study found a significant association between alcohol outlet density and male-to-female partner violence, but no significant association for female-to-male violence. The study controlled for a substantial amount of individual-, couple- and zip code-level sociodemographic factors, and examined self-reported alcohol consumption along with outlet density, finding that the effect of outlet density on domestic violence was stronger for couples who reported bingedrinking behaviour. When the results were broken down by type of outlet, on-premise outlet density was significantly related to partner violence rates, while off-premise outlet density was not. Neither of the ecological studies (Gorman et al., 1998; Chikritzhs et al., 2007) controlled for the effects of spatial autocorrelation, which can result in biases in statistical testing (Gruenewald and Remer, 2006).

Theoretically, a causal relationship between alcohol outlet density and domestic violence could be based on one of two mechanisms. Most obviously, it is plausible that higher levels of alcohol outlet density cause higher alcohol consumption, leading to increased rates of domestic violence. This is given some support by the clear links between alcohol consumption and domestic violence (e.g. Leonard, 2001; Foran and O'Leary, 2008) and by the studies finding positive associations between alcohol outlet density and consumption (Godfrey, 1988; Gruenewald et al., 1993), although this finding is not uniform (Pollack et al., 2005). Secondly, Freisthler (2004) has suggested that alcohol outlets alter residents routine activities, with increases in off-premise outlets resulting in a shift towards drinking at home (and thus higher rates of child physical abuse), and increases in on-premise outlets resulting in a shift towards drinking outside the home (with corresponding increases in child neglect). It is possible that similar changes to routine drinking activities directly bear on the likelihood of domestic violence incidents with, particular types of outlets encouraging different drinking patterns without necessarily altering overall consumption. For example, increases in pubs and hotels may lead to more frequent episodes of intoxication and thus increased domestic violence, while increases in packaged liquor outlets could shift drinking into the home, with potential increases in domestic problems due to increased exposure. Contrastingly, increases in restaurants and cafes may shift some residents to more moderate drinking patterns, thus reducing the likelihood of intoxication and domestic violence. It is worth noting that these two rationales are interconnected - routine drinking activities may change along with total consumption, with for example, increased consumption overall along with increases in drinking to intoxication. Based on these two theoretical perspectives, it is expected that overall densities of alcohol outlets will be positively associated with domestic violence rates, and that densities of pubs and packaged liquor stores will be particularly strongly associated with violence.

It is possible that alcohol outlets and domestic violence are positively associated with no true causal link. For example, alcohol outlets may be markers of social disorganisation, or a lack of collective efficacy, which have been shown to have significant relationships with domestic violence rates (O'Campo et al., 1995; Miles-Doan and Kelly, 1997; Grisso et al., 1999; Cunradi et al., 2000; Bartolo, 2001; Browning, 2002; Pearlman et al., 2003; Cunradi, 2007). In this case, unless alcohol 
outlets represent specific causes of social disorganisation, any relationship between outlet density and domestic violence would only be detected when neighbourhood levels of social disorganisation were not controlled for. The results of Gorman et al. (1998) analysis from New Jersey, USA suggest this explanation, with the effects of outlet density disappearing once socio-demographic factors were controlled for. Contrastingly, McKinney et al. (2009) found a significant association between outlet density and partner violence even while controlling for a wide range of socio-demographic factors, consistent with a causal relation mediated by increased consumption.

The present study tests the statistical association between alcohol outlet density and domestic violence in Melbourne, Australia. The study will provide further analysis of an under-researched question: is the availability of alcohol related to the incidence of domestic violence? The association between outlet density and domestic violence rates will be examined with and without socio-demographic control variables to examine whether any associations found with outlet density are mediated by socio-demographic factors.

\section{Materials and methods}

Aggregated data from administrative sources were used to examine the associations between alcohol outlet density and police-recorded domestic violence rates. Analyses were undertaken both with and without a range of neighbourhood characteristics controlled for to assess whether alcohol outlet density was associated with domestic violence over and above other measures of social deprivation.

\section{Geographical units}

The study uses postcode-level data for the greater Melbourne area, approximately $5,600 \mathrm{~km}^{2}$ containing the city of Melbourne and its surrounding suburbs. Postcodes are the smallest unit for which reliable liquor licensing and police data are available, and are generally good approximations for local suburbs. In 2001 there were 222 postcodes in the greater Melbourne area, with approximately $3,350,000$ residents. The analyses were limited to Melbourne to avoid the difficulties associated with analysing rural and urban postcodes in the same models. Initial analyses resulted in five postcodes being excluded from the study, leaving 217 postcodes for the final analyses. Two of the excluded postcodes represented particularly unusual land uses and low residential populations (i.e. an airport and a military base), while three others were innercity postcodes with very high outlet numbers and few residents.

\section{Measures}

Domestic violence incident data were provided by the Victorian Police Service from their Law Enforcement Assistance Program (LEAP) database. The data used are counts of "family incidents" recorded by the police for each postcode in the study area in the financial year 2001/2002. Family incidents include any incident reported to the police where the police determine that a crime has been committed and that there is an intimate relationship between the offender and the victim (e.g. married, divorced, child/parent, de-facto etc). The majority of these incidents involve incidents of domestic violence involving people in couple relationships (or whose couple relationship is now over), and around $80 \%$ of the incidents involved male offenders and female victims. This contrasts somewhat with survey derived estimates of domestic violence, which generally find roughly equal numbers of male and female victims (e.g. Graham et al., 2008). However, generally female victims experience more severe violence and are more likely to be injured (Graham et al., 2008). Thus, as offences involving police are likely to be at the more serious end of the spectrum, it is not surprising that the majority of offences dealt with in the current study involve female victims. The postcode recorded is for the locality in which the offence takes place, which is generally the victim's 
residence. It should be noted that using a policing driven measure of domestic violence creates the potential for biases in the analyses (e.g. policing effort may be more intense in some areas and thus more likely to record incidents in those areas). In addition, many incidents of domestic violence are likely to be excluded from police-based statistics with, for example, the Australian 2005 Personal Safety Survey (Australian Bureau of Statistics, 2006) finding that just $36 \%$ of female victims of physical assault reported the incident to the police. This represents a significant source of potential bias to the study, particularly if reporting rates vary along with the availability of alcohol. There is little published research on factors influence the reporting of domestic violence in Australia, although there is research from the US indicating, for example, that non-white victims are more likely to report domestic violence, so the risk of bias from this measure is not negligible. However, police data is often used in these kinds of analyses (e.g. Miles-Doan and Kelly, 1997; Bartolo, 2001; Britt et al., 2005; Gorman et al., 2005), and the use of a range of control variables related to police reporting rates (e.g. socioeconomic disadvantage) will ameliorate this bias somewhat. While previous studies have used counts or rates based on geographic measures, the fact that offences took place in residential settings meant that it was reasonable to calculate rates on a per 1,000 population basis.

Alcohol outlet data were provided by the Licensing Branch of the Victorian Department of Consumer Affairs. The licensing data provided included full address details for each premise, including postcode. Two-hundred random records were checked to assess the accuracy of the postcode field, with accurate data noted in $98 \%$ of cases. Three categories of licences are examined in this study: packaged liquor, general and on-premise. Packaged liquor licences allow for the sale of alcohol for off-premise consumption only and are generally specialised alcohol stores or small grocery stores. General licences allow for the sale of alcohol for either on- or off-premise consumption and are largely pubs and taverns - places where drinking is the primary activity and where alcohol can be sold to be consumed elsewhere. On-premise licences allow only for on-premise sales and include cafes, restaurants, bars and nightclubs. On-premise licences include a broad range of premises, but are predominantly restaurants and small bars. In 2001, these licence categories made up $61 \%$ of all licences in Victoria, with the remainder made up of registered clubs, producer-distributors and limited licences. Correlations between licence densities of the three types were examined and, while on-premise and general licence densities were highly correlated (0.7), tests for multicollinearity in the final models did not find significant problems due to correlated dependent variables. Outlet densities were calculated for each of the three categories examined on a population basis as rates per 1,000 residents ${ }^{1}$.

The remaining data for the study were sociodemographic measures sourced from the Australian 2001 Census of Population and Housing Basic Community Profiles (Australian Bureau of Statistics, 2002). The particular measures chosen were selected based on their significant associations with violence in previous studies of outlet density and on their significance in studies examining the ecological predictors of domestic violence. In particular, socio-economic status has repeatedly been linked with rates of domestic violence, as have measures of race and the proportion of residents who own their own homes (MilesDoan and Kelly, 1997; Bartolo, 2001; McKinney et al., 2009). Thus, this study includes three measures of socio-economic disadvantage: a composite measure, the index of relative socio-economic disadvantage (IRSED) derived from 2001 census data, the unemployment rate for each postcode and the proportion of households in each postcode which were owner-occupied. The IRSED is a composite measure based on numerous variables including

\footnotetext{
1 Similar analyses were undertaken using outlets per $\mathrm{km}^{2}$ rather than per-capita, with no substantive change to the study's findings.
} 
educational attainment, household income and single-parent families. This measure provides an overall estimate of the socio-economic disadvantage of an area, without introducing collinearity (correlation between two or more variables under analysis; Cohen, 2003), by including multiple measures of the same underlying construct, e.g. the proportion of people on low incomes and those with low educational attainment are highly correlated. Full details of the derivation of the IRSED have been published by the Australian Bureau of Statistics (2003). In addition, the proportion of the population in each postcode who spoke a language other than English was included as a measure of cultural diversity. Population instability has also been linked with social disorganisation, lack of collective efficacy and domestic violence (Morenoff et al., 2001; Stover, 2005), so a measure of population turnover (the proportion of the population in each postcode who had moved in the last five years) was also examined. Finally, a measure of population density (residents per $\mathrm{km}^{2}$ ) was examined to account for the varying geographic sizes of the units of analysis.

\section{Analysis}

All analyses were undertaken using the " $\mathrm{R}$ " statistical software package ( $\mathrm{R}$ Development Core Team 2006), with the "spdep" package (Bivand, 2006) used for all spatial analyses. The "spdep" package is an add-on to " $\mathrm{R}$ ", providing a number of tools for spatial analysis, including calculation of spatial autocorrelation and spatially appropriate regression models. These tools allow for the appropriate analysis of data based on spatial units, where the underlying assumption of standard regression models that study units are independent is likely to be broken.

The unit of analysis throughout the study was the postcode. The dependent variable for all analyses was the rate of police recorded family incidents per 1,000 residents. The independent variables were the three categories of alcohol outlet density, the
IRSED index of disadvantage, the unemployment rate, the proportion of households owner-occupied, the proportion of residents who had moved in the previous 5 years and the population density (residents per $\mathrm{km}^{2}$ ).

Tests for multicollinearity were undertaken throughout the analysis. A regression model involving highly correlated independent variables (e.g. variables measuring poverty, unemployment and education levels) can produce misleading results, due to the overlaps in variance being explained by the correlated variables. Thus, models were checked to ensure that the independent variables included did not produce models overly affected by multicollinearity.

An initial series of ordinary-least squares linear regression models were developed. The first model included only the alcohol outlet density variables as independent variables and the second model added all the socio-demographic variables. Diagnostic analyses undertaken at this point resulted in the exclusion of the unemployment rate and the proportion of households that were owner-occupied from the final model due to multicollinearity (variance inflation factors $>5$ ). This is not surprising, as both unemployment and housing tenure variables are included in the calculation of the IRSED index. The final model incorporating the alcohol outlet variables and the remaining socio-demographics was then produced.

At this stage, an assessment of the level of spatial autocorrelation in the residuals of the final model was examined. Spatial autocorrelation was examined based on neighbouring postcodes. Thus, the connection matrix included $1 \mathrm{~s}$ where postcodes were direct neighbours and 0 s otherwise. The Moran's $I$ coefficient of the residuals was significant $(I=0.12 ; \mathrm{P}<0.01)$ indicating possible bias due to spatial autocorrelation. An examination of the Lagrange Multiplier Test Statistics suggested that a spatial error model was appropriate to control for these possible biases, and a maximum likelihood estimation of a spatial error model was developed (Ward and Gleditsch, 2008). 


\section{Results}

Descriptive statistics for the variables used in this study are provided in Table 1 . The bi-variate correlations between each of the independent measures and the domestic violence rate are provided in the table, indicating a strong association between measures of socio-economic disadvantage and domestic violence, and a positive association between general licence density and domestic violence.

The OLS regression models are presented in Table 2. The first model includes only the alcohol outlet density variables, and the second adds in the sociodemographic variables discussed previously. As mentioned in the previous section, the unemployment rate and proportion of households that owned their own home were excluded from the modelling as they were highly collinear with the IRSED index. The initial model finds a positive and significant association between general outlet density and domestic violence rates and a negative and significant association between on-premise outlet density and domestic violence. There is no significant association between packaged licence density and domestic violence rates.

Table 1. Descriptive statistics of key study measures and correlation between independent variables and domestic violence rate.

\begin{tabular}{|c|c|c|c|c|c|}
\hline Measures & Minimum & Maximum & Median & Mean & $\begin{array}{l}\text { Pearson correlation } \\
\text { with domestic } \\
\text { violence rate }\end{array}$ \\
\hline General licences density ${ }^{a}$ & 0.0 & 3.3 & 0.1 & 0.3 & $0.27 * *$ \\
\hline On premise licence density ${ }^{\mathrm{a}}$ & 0.0 & 10.9 & 0.5 & 0.9 & $0.04 * *$ \\
\hline Packaged licence density ${ }^{\mathrm{a}}$ & 0.0 & 1.5 & 0.2 & 0.3 & $0.06 * *$ \\
\hline IRSED index & 707.0 & 1152.0 & 1048.0 & 1034.0 & $-0.67 * *$ \\
\hline Population per $\mathrm{km}^{2}$ & 0.01 & 6.4 & 1.6 & 1.6 & $0.09 * *$ \\
\hline Unemployment rate & 2.2 & 22.3 & 5.2 & 6.3 & $0.62 * *$ \\
\hline$\%$ moved in last 12 months & 5.9 & 41.8 & 14.8 & 16.2 & $0.13 *$ \\
\hline$\%$ households owner-occupied & 18.5 & 91.2 & 74.7 & 70.9 & $-0.31 * *$ \\
\hline$\%$ non-English speaking background & 1.8 & 77.1 & 20.0 & 24.0 & $0.27 * *$ \\
\hline Domestic violence rate $\mathrm{e}^{\mathrm{b}}$ & 0.0 & 17.8 & 4.0 & 4.6 & $1.00 * *$ \\
\hline
\end{tabular}

${ }^{a}$ Outlets per 1,000 residents; ${ }^{b}$ Police recorded domestic violence incidents per 1,000 residents; ${ }^{*} \mathrm{P}<0.05 ; * \mathrm{P}<0.01$

Table 2. Results of OLS regression with domestic violence rate as the independent variable, reduced (model 1) and full (model 2) models.

\begin{tabular}{|c|c|c|c|c|c|c|c|c|}
\hline \multirow[t]{2}{*}{ Variable } & \multicolumn{4}{|c|}{ Model 1} & \multicolumn{4}{|c|}{ Model 2} \\
\hline & $\mathrm{b}$ & & $\mathrm{CI}$ & & $\mathrm{b}$ & & $\mathrm{CI}$ & \\
\hline General licence density & $2.29 * *$ & 3.79 & - & 4.97 & $1.22 * *$ & 0.55 & - & 1.88 \\
\hline Packaged licence density & 0.21 & -1.44 & - & 1.87 & -0.37 & -1.55 & - & 0.81 \\
\hline On-premise licence density & $-0.55 * *$ & -0.89 & - & -0.20 & $-0.29 *$ & 0.57 & - & -0.02 \\
\hline IRSED index & $4.38 * *$ & 3.79 & - & 4.97 & $-0.03 *$ & 0.38 & - & -0.28 \\
\hline$\%$ population moved in last 12 months & & & & & 0.00 & -0.06 & - & 0.06 \\
\hline$\%$ population with non-English speaking background & & & & & $-0.07 * *$ & 0.09 & - & -0.04 \\
\hline Population density & & & & & $0.48 * *$ & 0.20 & - & 0.75 \\
\hline Constant & & & & & $39.61 * *$ & 34.31 & - & 44.91 \\
\hline Adjusted R-squared & 0.09 & & n.a. & & 0.55 & & n.a. & \\
\hline Moran's I coefficient & $0.23 * *$ & & n.a. & & $0.12 * *$ & & n.a. & \\
\hline
\end{tabular}

$* \mathrm{P}<0.05 ; * \mathrm{P}<0.01 ; \mathrm{CI}=$ confidence interval; n.a. = not assessed 
The model was not a good fit to the data, explaining only $9 \%$ of the variance in domestic violence rates.

When the socio-demographic variables were added to the model, the direction and significance of the associations between the outlet density variables and domestic violence rates remained, although the magnitude of the effects for both general outlets and on-premise outlets were roughly halved. The IRSED was highly significant, suggesting that postcodes with lower socio-economic status had higher reported domestic violence rates. Similarly, the model suggests that postcodes with high population density have higher rates of domestic violence. The proportion of residents from non-English speaking households was negatively associated with domestic violence rates, and there was no significant relationship between population mobility and domestic violence. This expanded model provided a much better fit to the data, explaining around $55 \%$ of the variance in domestic violence rates.

Tests of the Moran's I coefficient for each model indicated substantial levels of spatial autocorrelation. To ensure that the final results were not biased due to spatial dependence, spatial error models were developed. The results of these models are presented in Table 3. While the spatial parameter was significant in both models, the overall results are not markedly different from those derived using OLS techniques (Table 2). The fit of the full OLS and full spatial error models were compared using the Akaike information criterion (AIC) (Akaike, 1974). The AIC measures the goodness of fit of regression models across varying model-fitting methods (measures such as the R-squared are not appropriate to compare maximum likelihood estimated spatial models with OLS regression models). Lower values of the AIC represent models that use the fewest parameters possible to best fit the data. The OLS model had an AIC of 905.9, while the spatial error model had an AIC of 898.7 , indicating a slightly better fit. Thus the spatial error model was considered the better fitting model and will be the focus of the discussion. In terms of the licence density variables, general licences were significantly positively associated with domestic violence, while on-premise licences were significantly negatively associated with it. An increase of general licence density of one outlet per 1,000 residents was associated with an increase of 1.35 reported incidents of domestic violence per 1,000 residents. Similarly, an increase of 1 on-premise outlet per 1,000 residents was associated with a decrease of 0.34 incidents of domestic violence per 1,000.

Table 3. Maximum likelihood spatial error model results.

\begin{tabular}{|c|c|c|c|c|c|c|c|c|}
\hline \multirow{3}{*}{$\begin{array}{l}\text { Variable } \\
\text { General licence density }\end{array}$} & \multicolumn{4}{|c|}{ Model 1} & \multicolumn{4}{|c|}{ Model 2} \\
\hline & \multirow{2}{*}{$\frac{b}{2.29 * *}$} & \multicolumn{3}{|c|}{$95 \% \mathrm{CI}$} & \multirow{2}{*}{$\frac{b}{1.35 * *}$} & \multicolumn{3}{|c|}{$95 \% \mathrm{CI}$} \\
\hline & & 1.41 & - & 3.16 & & 0.69 & - & 2.00 \\
\hline Packaged licence density & 1.15 & -0.35 & - & 2.64 & 0.10 & -1.02 & - & 1.22 \\
\hline On-premise licence density & $-0.44 *$ & -0.77 & - & -0.10 & $-0.34 *$ & -0.60 & - & -0.08 \\
\hline IRSED index & $4.03 * *$ & 3.25 & - & 4.81 & $-0.034 * *$ & -0.039 & - & -0.029 \\
\hline$\%$ population moved in last 12 months & & & & & 0.022 & -0.035 & & 0.079 \\
\hline$\%$ population with non-English speaking background & & & & & $-0.069 * *$ & -0.094 & - & -0.045 \\
\hline Population density & & & & & $0.36 *$ & 0.07 & - & 0.65 \\
\hline Constant & & & & & $40.55 *$ & 34.85 & - & 46.05 \\
\hline Spatial parameter $(\lambda)$ & 0.477 & & $=0$ & & 0.336 & & 0. & \\
\hline
\end{tabular}

$* \mathrm{P}<0.05 ; * * \mathrm{P}<0.01 ; \mathrm{CI}=$ confidence interval 


\section{Discussion}

This study has demonstrated a statistical association between the density of alcohol outlets and police-recorded domestic violence rates at the postcode level in Melbourne, Australia. The study finds a positive association between general (pub) licence density and domestic violence and a weaker, negative association between on-premise (restaurant, etc.) licence density and domestic violence.

The study provides the first aggregate analyses of the relationship between alcohol outlet density and rates of domestic violence to adequately control for the spatial dependence of the units of analysis. In addition, it examines specific outlet types and incorporates controls for socio-demographic factors likely to covary with outlet density and domestic violence rates. The study is limited by its use of police data, which are likely to underestimate the true rate of domestic violence and may result in biases in the findings.

In broad terms, the results of this study are consistent with previous research in this field. Domestic violence rates are highly correlated with levels of socio-economic disadvantage (Bartolo, 2001; Browning, 2002; Pearlman et al., 2003; McKinney et al., 2009). There is a significant and negative relationship between the proportion of residents from non-English speaking backgrounds and domestic violence, which has not been found in previous studies of domestic violence (most of which are from the US and are based on specific race data). This result does find support from a previous study of general assault rates in the same jurisdiction, with a similar negative effect found for ethnic diversity (Livingston, 2008a). There are a number of possible explanations for this relationship. While there is little data available on the prevalence of domestic violence in non-English speaking communities in Australia, evidence from the Women's Safety Survey suggests that these women experience lower rates of violence than the rest of the Australian population (The Women's Services Network, 2000). This may be partly due to lower alcohol consumption amongst these groups (Australian Institute of
Health and Welfare, 2009). In addition, there is some evidence that people from minority racial groups are less likely to report crimes to the police (Shah and Pease, 1992), which may result in their under-representation in the data used in the current study.

The findings for the alcohol availability variables were mixed, with a positive effect found for general licence density (hotels, pubs, etc.) and a negative effect for on-premise licence density (restaurants, bars, etc.). These associations were considerably weakened by the inclusion of a range of socio-demographic variables in the models, but remained significant. Hotels and pubs have previously been identified as particularly problematic venues for general levels of violence (Briscoe and Donnelly, 2001; Livingston, 2008b), while restaurant licences have been found to be associated with lower rates of general violence in other jurisdictions (e.g. Zhu et al., 2004). These findings provide support to Freisthler's theory of alcohol availability affecting people's routine drinking activities, with higher densities of alcohol-focussed venues (general licences) associated with increased domestic violence, while densities of less alcohol-focussed venues (on-premise licences) associated with reduced domestic violence. Traditionally, hotels and pubs have been the site of heavy drinking and drinking at these venues may be particularly likely to involve drinking to intoxication (Room, 1988). However, the lack of relationship between packaged liquor density and domestic violence was surprising in the context of this theory, which suggests that increased availability of packaged liquor leads to increased consumption within the home, which may increase the risk of incidents of domestic violence.

The relationship between density of on-premise licences (restaurants, cafes, bars, etc.) and domestic violence is negative, with higher densities of onpremise outlets related to lower levels of domestic violence, which may be due to the more moderate drinking styles associated with these kinds of premises. However, it seems unlikely that this relationship is due to the actual outlets themselves exerting 
protective effects, and instead reflects unmeasured socio-economic or demographic factors that vary along with on-premise licence density. This then raises the question of whether the effect found for general licences is a similar artefact and whether there are unmeasured neighbourhood factors related to both general licence density and domestic violence rates. For this reason, along with the limitations identified in the measures used in this study, the results presented here can point only to tentative implications for policy. The finding that general licences are positively associated with domestic violence rates, combined with previous work which found strong links between general licence density and assault in Melbourne (Livingston et al., 2007; Livingston, 2008a) suggest that the trend towards increasing numbers of these licences in Melbourne needs to be curtailed.

\section{Conclusions}

The results presented here provide support to previous findings linking alcohol outlet density to domestic violence (Chikritzhs et al., 2007; McKinney et al., 2009). When these results are considered alongside previous work examining the broader impacts of alcohol outlet density (Livingston et al., 2007), the policy implications are clear: efforts to stem the ongoing increases in alcohol availability in Victoria are required. However, the specific policy approaches required depend on a deeper understanding of the mechanisms of the link between alcohol outlets and domestic violence. While this paper has provided a first step in that direction, there remain uncertainties about the precise nature of this relationship. Future studies making use of longitudinal data are required to better understand the influence of alcohol availability on domestic violence.

\section{Acknowledgements}

This study was funded by the Alcohol Education and Rehabilitation Foundation and the Sidney Myer Foundation.
Helpful comments on the manuscript were made by Paul Dietze and Robin Room.

\section{References}

Akaike H, 1974. A new look at statistical model identification. IEEE Trans Automat Contr 19, 716-723.

Australian Bureau of Statistics, 2002. National census of population and housing basic community profiles. Australian Bureau of Statistics, Canberra, Australia.

Australian Bureau of Statistics, 2003. Information paper: census of population and housing - socio-economic indexes for areas, Australia, 2001. Australian Bureau of Statistics, Canberra, Australia.

Australian Bureau of Statistics, 2006. Personal safety survey Australia. Australian Bureau of Statistics, Canberra, Australia.

Australian Institute of Health and Welfare, 2009. 2007 national drug strategy household survey - detailed findings. Australian Institute of Health and Welfare, Canberra, Australia.

Bartolo LD, 2001. The geography of reported domestic violence in Brisbane: a social justice perspective. Aust Geogr 32, 321-341.

Bivand R, 2006. spdep: spatial dependence: weighting schemes, statistics and models. $\mathrm{R}$ package version 0.3-31.

Briscoe S, Donnelly N, 2001. Assaults on licensed premises in inner-urban areas. New South Wales Bureau of Crime Statistics and Research \& National Drug Research Institute. Britt HR, Carlin BP, Toomey TL, Wagenaar AC, 2005. Neighborhood level spatial analysis of the relationship between alcohol outlet density and criminal violence. Environ Ecol Stat 12, 411-426.

Browning CR, 2002. The span of collective efficacy: extending social disorganization theory to partner violence. J Marriage Fam 64, 833-850.

Chikritzhs T, Catalano P, Pascal R, Henrickson N, 2007. Predicting alcohol-related harms from licensed outlet density: a feasibility study. National Drug Law Enforcement Research Fund, Hobart, Australia.

Cohen J, 2003. Applied multiple regression/correlation analysis for the behavioral sciences. Lawrence Erlbaum.

Cunradi CB, 2007. Drinking level, neighborhood social disorder, and mutual intimate partner violence. Alcohol Clin 
Exp Res 31, 1012-1019.

Cunradi CB, Caetano R, Clark C, Schafer J, 2000. Neighborhood poverty as a predictor of intimate partner violence among white, black, and hispanic couples in the United States: a multilevel analysis. Ann Epidemiol 10, 297-308.

Foran HM, O'Leary KD, 2008. Alcohol and intimate partner violence: a meta-analytic review. Clin Psychol Rev 28, 1222-1234.

Freisthler B, 2004. A spatial analysis of social disorganization, alcohol access, and rates of child maltreatment in neighborhoods. Child Youth Serv Rev 26, 803-819.

Freisthler B, Gruenewald PJ, Remer LG, Lery B, Needell B, 2007. Exploring the spatial dynamics of alcohol outlets and child protective services referrals, substantiations, and foster care entries. Child Maltreat 12, 114-124.

Freisthler B, Midanik LT, Gruenewald PJ, 2004. Alcohol outlets and child physical abuse and neglect: applying routine activities theory to the study of child maltreatment. J Stud Alcohol 65, 586-592.

Freisthler B, Needell B, Gruenewald PJ, 2005. Is the physical availability of alcohol and illicit drugs related to neighbourhood rates of child maltreatment? Child Abuse Neglect 29, 1049-1060.

Freisthler B, Weiss RE, 2008. Using Bayesian space-time models to understand the substance use environment and risk for being referred to child protective services. Subst Alcohol Actions Misuse 43, 239-251.

Godfrey C, 1988. Licensing and the demand for alcohol. Appl Econ 20, 1541-1548.

Gorman DM, Labouvie EW, Speer PW, Subaiya AP, 1998. Alcohol availability and domestic violence. Am J Drug Alcohol Abuse 24, 661-673.

Gorman DM, Speer PW, Gruenewald PJ, Labouvie EW, 2001. Spatial dynamics of alcohol availability, neighborhood structure and violent crime. J Stud Alcohol 62, 628.

Gorman DM, Zhu L, Horel S, 2005. Drug 'hot-spots', alcohol availability and violence. Drug Alcohol Rev 24, 507-513.

Graham K, Bernards S, Munne M, Wilsnack S, 2008. Unhappy hours: alcohol and partner aggression in the Americas. Scientific and Technical Publications, Pan American Health Organization, Washington D.C., USA.

Grisso JA, Schwarz DF, Hirschinger N, Sammel M, Brensinger C, Santanna J, Lowe RA, Anderson E, Shaw LM, Bethel CA, 1999. Violent injuries among women in an urban area. N Engl J Med 341, 1899-1905.

Gruenewald PJ, 2007. The spatial ecology of alcohol problems: niche theory and assortative drinking. Addiction 102, 870-878.

Gruenewald PJ, Freisthler B, Remer L, LaScala EA, Treno A, 2006. Ecological models of alcohol outlets and violent assaults: crime potentials and geospatial analysis. Addiction 101, 666-677.

Gruenewald PJ, Ponicki WR, Holder HD, 1993. The relationship of outlet densities to alcohol consumption: a time series cross-sectional analysis. Alcohol Clin Exp Res 17, 38-47.

Gruenewald PJ, Remer L, 2006. Changes in outlet densities affect violence rates. Alcohol Clin Exp Res 30, 1184-1193. Gyimah-Brempong K, Racine J, 2006. Alcohol availability and crime: a robust approach. Appl Econ 38, 1293-1307.

Leonard K, 2001. Domestic violence and alcohol: what is known and what do we need to know to encourage environmental interventions? J Subst Use 6, 235-247.

Lipton R, Gruenewald PJ, 2002. The spatial dynamics of violence and liqour outlets. J Stud Alcohol 63, 187-195.

Livingston M, 2008a. Alcohol outlet density and assault: a spatial analysis. Addiction 103, 619-628.

Livingston M, 2008b. A longitudinal analysis of alcohol outlet density and assault. Alcohol Clin Exp Res 32, 1074-1079.

Livingston M, Chikritzhs T, Room R, 2007. Changing the density of alcohol outlets to reduce alcohol-related problems. Drug Alcohol Rev 26, 553-562.

Livingston M, Chikritzhs T, Room R, 2007. Changing the density of alcohol outlets to reduce alcohol-related problems. Drug Alcohol Rev 26, 557-566.

McKinney C, Caetano R, Harris T, Ebama M, 2009. Alcohol availability and intimate partner violence among US couples. Alcohol Clin Exp Res 33, 1-8.

Miles-Doan R, Kelly S, 1997. Geographic concentration of violence between intimate partners. Public Health Rep 112, 135-141.

Morenoff JD, Sampson RJ, Raudenbush SW, 2001. Neighborhood inequality, collective efficacy, and the spatial dynamics of urban violence. Criminology 39, 517-558.

Nielsen AL, Martinez R, Lee MT, 2005. Alcohol, ethnicity and violence: the role of alcohol availability for Latino and Black aggravated assaults and robberies. Soc Quart 46, 479-502.

Norström T, 2000. Outlet density and criminal violence in Norway, 1960-1995. J Stud Alcohol 61, 907-911. 
O'Campo P, Gielen AC, Faden RR, Xue X, Kass N, Wang MC, 1995. Violence by male partners against women during the childbearing year: a contextual analysis. Am Public Health Assoc 85, 1092-1097.

Pearlman DN, Zierler S, Gjelsvik A, Verhoek-Oftedahl W, 2003. Neighborhood environment, racial position, and risk of police-reported domestic violence: a contextual analysis. Public Health Rep 118, 44-58.

Pollack CE, Cubbin C, Ahn D, Winkleby M, 2005. Neighbourhood deprivation and alcohol consumption: does the availability of alcohol play a role. Int J Epidemiol 34, 772-780.

R Development Core Team, 2006. R: a language and environment for statistical computing. R Foundation for Statistical Computing, Vienna, Austria.

Reid RJ, Hughey J, Peterson NA, 2005. Generalizing the alcohol outlet-assaultive violence link: evidence from a U.S. Midwestern city. Subst Alcohol Actions Misuse 38, 19711982.

Room R, 1988. The dialectic of drinking in Australian life: from the Rum Corps to the wine column. Aus Drug Alcohol Rev 7, 413-437.

Scribner RA, Cohen DA, Kaplan S, Allen SH, 1999. Alcohol availability and homicide in New Orleans: conceptual con- siderations for small area analysis of the effect of alcohol outlet density. J Stud Alcohol 60, 310-316.

Shah R, Pease K, 1992. Crime, race and reporting to the police. Howard J Crim J 31, 192-199.

Stevenson RJ, Lind B, Weatherburn D, 1999. The relationship between alcohol sales and assault in New South Wales, Australia. Addiction 94, 397-410.

Stover CS, 2005. Domestic violence research: what have we learned and where do we go from here? J Interpers Violence 20, 448-454.

The Women's Services Network, 2000. Domestic violence in regional Australia - a literature review. Commonwealth Department of Transport and Regional Services. Canberra, Australia.

Ward MD, Gleditsch KS, 2008. Spatial regression models. SAGE, London, UK.

Yu Q, Scribner R, Carlin BP, Theall K, Simonsen N, GhoshDastidar B, Cohen DA, Mason K, 2008. Multilevel spatiotemporal dual changepoint models for relating alcohol outlet destruction and changes in neighbourhood rates of assaultive violence. Geospat Health 2, 161-172.

Zhu L, Gorman DM, Horel S, 2004. Alcohol outlet density and violence: a geospatial analysis. Alcohol Alcohol 39, 369-375. 